\title{
Pitfalls and solutions in case fatality risk estimation - A multi-country analysis on the effects of demographics, surveillance, time lags between case reports and deaths and healthcare system capacity on COVID-19 CFR estimates
}

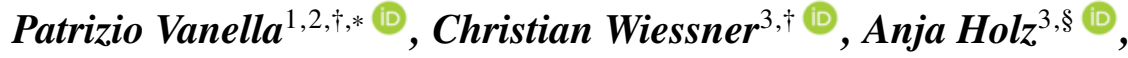 \\ Gérard Krause $^{1,4, \S} \mathbb{1}^{\circ}$, Annika Möhl ${ }^{3, \S}$ (1), Sarah Wiegel ${ }^{3, \S}$, \\ Berit Lange $^{1,4,+(1)}$ and Heiko Becher ${ }^{3,+}$ (i)
}

\section{Abstract}

Across European countries, there have been large differences in COVID-19 case fatality risk (CFR) estimates, and considerable variation in these estimates over time. CFR estimates vary depending on both the method used for estimation and countryspecific characteristics. While crude methods simply use cumulative total numbers of cases and deaths, the CFR can be influenced by the demographic characteristics of the cases, the case detection rates, the time lags between the reporting of infections and deaths and infrastructure characteristics, such as healthcare capacities. We use publicly available weekly data for 11 European countries on the COVID19 case and death numbers by age group for the year 2020. Moreover, we use data on national weekly test rates to adjust the case numbers, and to investigate the effects of different time lags between the reporting of cases and deaths on the estimation of CFRs. Finally, we describe the association between case fatality

\footnotetext{
${ }^{1}$ Department of Epidemiology, Helmholtz Centre for Infection Research (HZI), Brunswick, Germany ${ }^{2}$ Chair of Empirical Methods in Social Science and Demography, University of Rostock, Rostock, Germany

${ }^{3}$ Institute of Medical Biometry and Epidemiology, University Medical Center Hamburg-Eppendorf (UKE), Hamburg, Germany

${ }^{4}$ German Center for Infection Research (DZIF), Brunswick, Germany

${ }^{\dagger}$ Shared first authors

¥Shared last authors

${ }^{\S}$ In alphabetical order

*Correspondence to: Patrizio Vanella, patrizio.vanella@helmholtz-hzi.de
} 
rates and the demand for hospital and intensive care unit beds for COVID-19 cases, while taking into account national bed capacities. The crude CFR estimates differ considerably across the investigated countries. In the crude international CFR time series, the differences are smaller when adjusting for the demographics of the cases. Differences in testing policies significantly affect the CFR estimates as well. However, the question of precisely how these testing procedures should be adjusted requires further investigation. Lag adjustments of CFRs do not lead to improvements in estimates of COVID-19 CFRs, and no connection between hospital capacities and CFRs can be found for the countries included in our study.

Keywords: COVID-19 pandemic; epidemiological surveillance; case fatality risk; demographics; vulnerable populations; testing policy; healthcare; public health

\section{Introduction and background}

Countries' COVID-19 case fatality risk (CFR) estimates vary considerably. Crude CFR estimates - i.e., the cumulative number of deaths divided by the cumulative number of cases - are known to be biased (Lipsitch et al., 2015). The main sources of bias are shown in Table 1. A distinction must be made between factors that might influence actual lethality, such as healthcare capacity, and those that bias the estimates of the CFR, such as an underassessment of the number of cases. One asterisk denotes factors that may affect the actual CFR, whereas two asterisks refer to factors that simply bias the CFR estimate.

Differences in CFRs across countries might be explained by differences in the demographic characteristics of infected cases, such as age, comorbidities or underlying risk factors; as well as differences in the underlying population structures of the respective countries (Dudel et al., 2020). There is evidence that being older and having comorbidities - such as hypertension, diabetes, cardiovascular disease or chronic lung disease - are major risk factors for severe COVID-19 infection outcomes (Fernández Villalobos et al., 2021; Jordan et al., 2020; Wu et al., 2020; Zhou et al., 2020). The higher susceptibility to disease and the higher prevalence of comorbidities among the elderly (Fernández Villalobos et al., 2021; Vanella et al., 2020) have an impact on the morbidity and mortality of this subpopulation (Gornyk et al., 2021). Thus, CFRs tend to be higher in countries with an older population than in countries with a younger age structure, including during the COVID-19 pandemic (Cai, 2020; Dudel et al., 2020; European Centre for Disease Prevention and Control, 2020a; Shim et al., 2020; Wu et al., 2020; Wu and McGoogan, 2020; Xie et al., 2020; Yang et al., 2020; Zhang et al., 2020).

Differences in the surveillance systems and testing capacities of countries lead to huge variations across countries in the numbers of tests performed (European Centre for Disease Prevention and Control, 2020b, 2021b; Fang et al., 2020; Pan et al., 2020; Rajgor et al., 2020; World Health Organization, 2020b). Thus, the degree of underassessment of infections differs between countries (Lau et al., 2020; Li et al., 2020). Furthermore, surveillance and testing capacities influence the probability of 
Table 1:

Sources of bias of case fatality risk estimates

\begin{tabular}{|c|c|c|c|}
\hline Factor & Description & Impact on CFR estimates & Literature \\
\hline $\begin{array}{l}\text { Population } \\
\text { structure* }\end{array}$ & $\begin{array}{l}\text { Age, comorbidities } \\
\text { and underlying risk } \\
\text { factors }\end{array}$ & $\begin{array}{l}\text { Higher CFRs due to an } \\
\text { older population with a } \\
\text { higher load of } \\
\text { comorbidities }\end{array}$ & $\begin{array}{l}\text { Cai (2020); European Centre for } \\
\text { Disease Prevention and Control } \\
\text { (2020a); Gianicolo et al. (2020); } \\
\text { Shim et al. (2020); Wu et al. } \\
\text { (2020); Wu and McGoogan } \\
\text { (2020); Xie et al. (2020); Yang } \\
\text { et al. (2020); Zhang et al. (2020) }\end{array}$ \\
\hline \multirow[t]{3}{*}{$\begin{array}{l}\text { Surveillance } \\
\text { and testing }{ }^{* *}\end{array}$} & $\begin{array}{l}\text { Surveillance system } \\
\text { and different testing } \\
\text { capacities }\end{array}$ & $\begin{array}{l}\text { Overestimation of CFRs } \\
\text { due to a poor surveillance } \\
\text { system and low testing } \\
\text { capacities, as fewer } \\
\text { currently infected persons } \\
\text { in relation to deaths are } \\
\text { counted }\end{array}$ & $\begin{array}{l}\text { European Centre for Disease } \\
\text { Prevention and Control (2020b); } \\
\text { Lau et al. (2020); Li et al. (2020); } \\
\text { Lipsitch et al. (2015); Rajgor } \\
\text { et al. (2020); Reich et al. (2012); } \\
\text { World Health Organization } \\
\text { (2020a) }\end{array}$ \\
\hline & $\begin{array}{l}\text { Methods and } \\
\text { capacities for } \\
\text { recording deaths }\end{array}$ & $\begin{array}{l}\text { Underestimation of CFRs } \\
\text { due to low capacities and } \\
\text { poor quality methods for } \\
\text { recording deaths from the } \\
\text { disease, resulting in a } \\
\text { smaller numerator of deaths } \\
\text { to current reported } \\
\text { infections }\end{array}$ & Gordis (2014) \\
\hline & & $\begin{array}{l}\text { Overestimation of CFRs if } \\
\text { all deaths are counted } \\
\text { regardless of whether the } \\
\text { patient died of the target } \\
\text { disease or another cause } \\
\text { given the same number of } \\
\text { infections }\end{array}$ & Gordis (2014) \\
\hline Time lag** & $\begin{array}{l}\text { Deaths occur with a } \\
\text { time delay after } \\
\text { infections }\end{array}$ & $\begin{array}{l}\text { Underestimation of CFRs } \\
\text { due to a time lag of several } \\
\text { days between case } \\
\text { registrations and deaths, } \\
\text { resulting in a smaller } \\
\text { numerator of current deaths } \\
\text { to current infections }\end{array}$ & $\begin{array}{l}\text { Gianicolo et al. (2020); Wilson } \\
\text { et al. (2020) }\end{array}$ \\
\hline $\begin{array}{l}\text { Healthcare } \\
\text { system* }\end{array}$ & $\begin{array}{l}\text { Healthcare system } \\
\text { capacity measured } \\
\text { as the number of } \\
\text { intensive care beds } \\
\text { per } 100,000 \\
\text { inhabitants }\end{array}$ & $\begin{array}{l}\text { Higher CFRs due to low } \\
\text { healthcare capacities and } \\
\text { excessive demand for } \\
\text { intensive care beds during } \\
\text { the pandemic, resulting in } \\
\text { more deaths, and, therefore, } \\
\text { a higher numerator of } \\
\text { deaths to current infections }\end{array}$ & $\begin{array}{l}\text { Eriksson et al. (2017); European } \\
\text { Centre for Disease Prevention } \\
\text { and Control (2020a); Eurostat } \\
\text { (2019); Ji et al. (2020); } \\
\text { Legido-Quigley et al. (2020); } \\
\text { Rajgor et al. (2020); Rhodes et al. } \\
\text { (2012) }\end{array}$ \\
\hline
\end{tabular}

Note: ${ }^{*}$ Factors that may influence the actual CFR; ${ }^{* *}$ factors that bias the CFR estimates. 
detecting infections early, and of applying countermeasures in response. Countries may also differ in their capacities and methods for recording deaths caused by COVID-19. While some countries perform post-mortem screening of all deaths, other countries only perform post-mortem screening in cases considered clinically suspicious (Onder et al., 2020). Moreover, during the pandemic, countries have changed their testing strategies and the number of tests they perform multiple times (European Centre for Disease Prevention and Control, 2021b; Robert Koch Institut, 2020a, 2020b), which limits the representativeness of case time series on the country level.

There is a time lag between the reporting of an infection in an individual and his or her eventual death. The distribution of such time lags may differ between countries. These delays are not reflected in crude CFR estimates (Wilson et al., 2020). More robust estimates could be obtained by dividing cumulative deaths by cumulative recoveries. However, even these estimates are not reliable due to the low numbers of recoveries during the early stages of the pandemic, when a large relative increase in infection numbers and the incomplete reporting of recoveries were observed (Lipsitch, 2020). Therefore, some authors have proposed investigating the cumulative deaths in relation to lags of varying numbers of days for the cumulative infection numbers (Lipsitch, 2020; Wilson et al., 2020). However, due to the high transmission rates of the virus in the early stages of an epidemic, the estimates depend strongly on the lags, and both an underestimation and an overestimation of the true CFR can occur (Spychalski et al., 2020).

Furthermore, CFRs may be influenced by the healthcare system capacities of the affected countries. Previous studies have shown that healthcare capacities differ substantially across countries, and even between regions within countries (Eriksson et al., 2017; European Centre for Disease Prevention and Control, 2020a; Eurostat, 2019; Ji et al., 2020; Legido-Quigley et al., 2020; OECD, 2021a; Rajgor et al., 2020; Rhodes et al., 2012). When a country's healthcare system is overwhelmed by the pandemic, it may have higher CFRs.

While all of the factors mentioned above may help to explain the differences in the CFRs in the affected countries at different time points during the COVID19 pandemic, how much of the differences in CFR estimates during the pandemic are explained by each of these factors is unclear. This paper aims to quantify the effects of demographics, testing levels, delays in death after infection and demand for hospital beds on weekly COVID-19 CFR estimates. The countries were selected for the study based on whether they have a population of over eight million, and provide age-specific data on COVID-associated deaths and infections, either on their national health services web pages or in the COVerAGE database provided by the Max Planck Institute for Demographic Research. This selection process resulted in a sample of 11 European Union (EU) and Schengen area countries, ${ }^{1}$ which are examined during the year 2020 using a comparative perspective. The study shows

1 Belgium, France, Germany, Greece, Italy, the Netherlands, Portugal, Spain, Sweden, Switzerland and the United Kingdom. 
that these countries had different levels in the COVID-19 CFR time series, and, as we will see in the next section, that they accounted for a large share of the COVID19 disease burden in Europe over the study period.

In the following, we will show the time series of the crude CFRs for all study countries over the year 2020 . We will then present the data used in our study and our methodological approach. In a sequential approach, we will check whether adjustments of the crude CFRs to account for differences in demographics, testing, delays and the burden on the national health system as represented by hospitalisations can provide a more realistic picture of the actual fatality risks across countries and over time. We will consider the cross-national and intertemporal variations of the CFRs as a goodness-of-fit measure. In the following section, we will present the results of our investigation. We will end our contribution with a discussion and an outlook.

\section{Data and methods}

The crude CFR of country $j$ on day $\delta$ is estimated by dividing the cumulative number of official COVID-19 deaths $D_{i j \delta}$ for each age group $i$ by the cumulative number of COVID-19 cases $\hat{N}_{i j \delta}$, both until day $\delta$ and for each age group $i$ :

$$
\widehat{C F R}_{. j \delta}=\frac{D_{. j \delta}}{\hat{N}_{. j \delta}} .
$$

The hat underlines that the cases are the reported COVID-19 infections, which are a subset of all infections $N_{. j \delta}$. The crude CFR ignores all of the factors presented in the previous section. Figure 1 shows the development of the crude CFR estimates of the 11 study countries as percentages between 2 March and 31 December 2020, as provided by Dong et al. (2020). Figure 1(a) displays the estimates for the countries of central and northern Europe, whereas Figure 1(b) provides the estimates for the Mediterranean countries. The horizontal line marks the mean of the daily CFR estimates over the study period and all 11 study countries $(6.67 \%)$. The peak for the French data illustrates the data inconsistencies, which will be explained below.

All curves increase until late spring or early summer 2020, and then decrease again until the end of the study period, with some countries, such as Belgium and Greece, experiencing slight increases in their crude CFRs during the last weeks of the year. We observe significant differences between the curves. Our study aims to help explain these geographical and temporal differences, and to develop adjusted case fatality measures. The French and the Spanish lines in the right panel follow a rather jagged course. For France in particular, a sharp increase until early April can be observed, followed by a sharp decrease on 12 April, which is due to an almost doubling of the case numbers in the Johns Hopkins University (JHU) data on that date following the addition of French Ehpad data on cases reported for nursing homes (Johns Hopkins University, 2021; Ministère des Solidarités et de la Santé, 2021). Therefore, we find that there was a significant undercounting of 
Figure 1:

Crude case fatality risk estimates due to COVID-19 between 2 March and 31 December 2020 (the horizontal line represents the mean of the daily CFR estimates over all dates and countries)

a) Central and Northern Europe

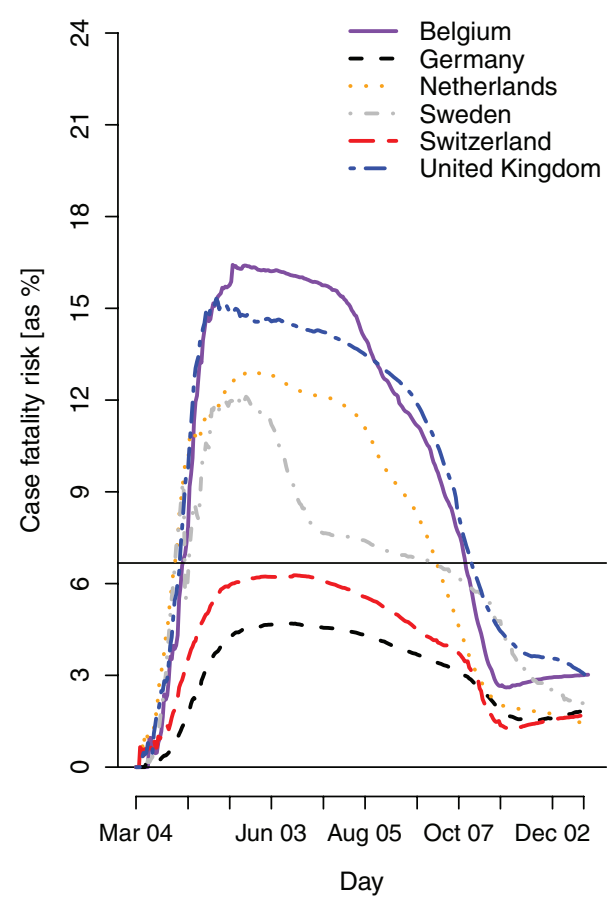

b) Mediterranean

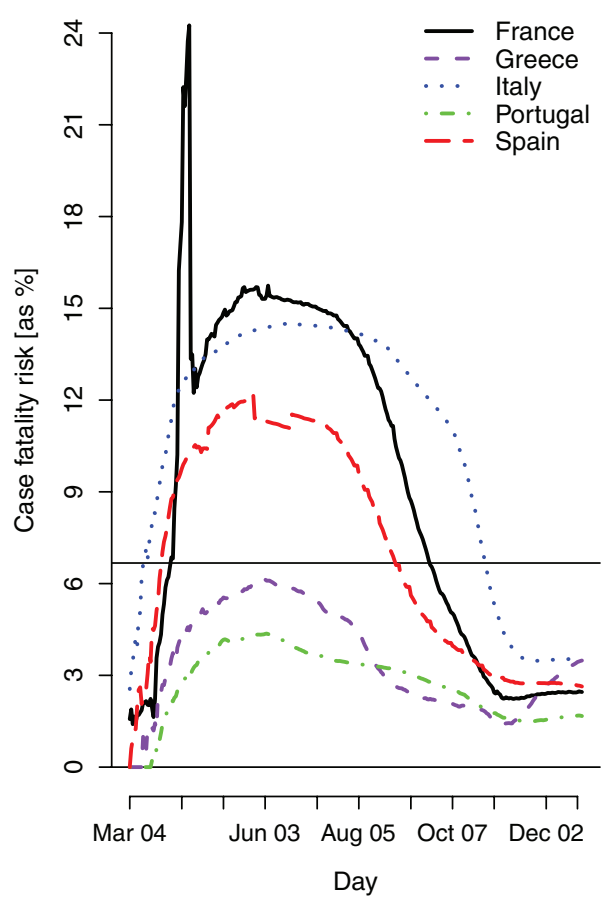

Source: Johns Hopkins University (2021); Own computation.

cases in France before that date that resulted in an overestimation of CFRs during that period. The tub-shaped line for Spain between mid-May and mid-June may be explained by a change in the reporting of the Spanish COVID-19 data during that time. Between mid-May and early July, Spanish authorities developed a new strategy for tracking and reporting COVID-19 data (Instituto de Salud Carlos III, 2020 b) that resulted in less detailed reports, which may, in turn, have led to the case data during that period being unrepresentative. While the crude CFR estimates had largely converged by the end of the year, there were still differences between the study countries. Sequentially, we will investigate how the cross-country and temporal variations can be explained by the abovementioned factors and mitigated by adjustments to the crude CFR. Since the variance is not an appropriate measure for comparing our different models, as it depends on the level of the variables, we compare our adjustments using the coefficient of variation (cv) of the different 
iterations, which is defined as the ratio of the standard deviation and the mean of a certain variable (Brown, 1998):

$$
c v(X)=\frac{s d(X)}{E(X)}
$$

\subsection{Step I: Adjustment to demographics}

In a first step, we investigate the effect of demographics on the CFR estimates. To do so, we gathered weekly data on cumulative age-specific case and death numbers from various sources for the study countries between early March and the end of 2020. The data for Germany have been downloaded from the Robert Koch Institute (RKI)'s Github database (Robert Koch Institut, 2021). For Italy, the data have been collected from early press releases and then regular reports published by the Istituto Superiore di Sanità (ISS) (2020a, 2020b, 2020c, 2020d). For the United Kingdom (UK), we downloaded data as provided from the website of the UK's national health authority (Public Health England, 2021a). For France, we found, after comparing different sources, that a combination of national reports from Santé publique France (2020a, 2020b) until calendar week 32 and data from the new COVerAGE database (Riffe et al., 2021a, 2021b) for the following period provided the best coverage of the age-specific case and death data, as we have observed significant irregularities and missing data for France. All of the data for the remaining seven countries came from the latter database. In our comparison of crude and age-adjusted CFRs, we use the European Standard Population (European Union, 2013) for standardisation. We use the following notation: for each country $j, d_{j k}$ is the number of deaths over all age groups observed during week $k$. Similarly, $\hat{n}_{. j k}$ is the number of observed new cases over all age groups during week $k$. Summing up the deaths up to week $w$, we obtain the total cumulative number of deaths in country $j$ over all ages $D_{j w}=$ $\sum_{k=1}^{w} d_{j k}$. Similarly, summing up the cumulative number of cases up to week $w$, we obtain $\hat{N}_{. j k}=\sum_{k=1}^{w} \hat{n}_{. j k}$, the total cumulative number of cases for country $j$ and up to week $w$.

While the numbers of cases and deaths in week $k$, for each country $j$ and age group $i$, are observed (respectively, $\hat{N}_{i j k}$ and $D_{i j k}$ ), the number of new infections in age group $i$, country $j$ and week $k$ (denoted by $n_{i j k}$ ) is latent (unknown). The number of cumulative infections in this group up to week $w$ is $N_{i j k}=\sum_{k=1}^{w} n_{i j k}$. Our first aim is to identify the role of the age structure of the cases in the overall CFRs, and to derive age-specific and age-standardised CFR estimates for all study countries. Based on the cumulative age-specific case numbers $\hat{N}_{i j k}$ of the 11 European countries, we calculate age-specific CFR estimates

$$
C F R_{i j k}=\frac{D_{i j k}}{\hat{N}_{i j k}}
$$


Multiplying these estimates with population weights derived from the European Standard Population, we obtain age-adjusted CFR estimates

$$
C F R_{j k}^{a g e}=\sum_{i} w_{i} \times C F R_{i j k}
$$

\subsection{Step II: Adjustment of age-specific cases to the level of surveillance}

In the second step, we investigate the impact of the surveillance of cases, as represented by time series data of weekly national tests provided by the European Centre for Disease Prevention and Control (ECDC) (2021b). As the ECDC does not provide corresponding test data for Switzerland and the UK, we obtained these data for these two countries from their respective national health services (Federal Office of Public Health, 2021; Public Health England, 2021b). However, age-specific data on testing for the first year of the pandemic were not available in time series form. Since symptoms vary by age (Davies et al., 2020), the detection rates of cases are age-specific. We deal with this data restriction indirectly by conducting principal component analysis (PCA). PCA is a data reduction technique that transforms the original, correlated variables into linear combinations that are uncorrelated, and are referred to as principal components (PCs) (Vanella, 2018). Working with PCs allows us to cover indirectly simultaneous trends and sensitivities of the case numbers to the testing strategy. As we lack age-specific data on testing for the first year of the pandemic, we cannot directly estimate the sensitivities of the age-specific case numbers to the testing strategy on a population level. Therefore, our approach is to approximate the different sensitivities of the age-specific case numbers to the testing strategy indirectly by estimating the sensitivity of the country-specific PCs to adjustments in the test numbers (irrespective of the age groups). We assume that the case numbers are influenced by the test numbers, but to differing degrees depending on age, as both the symptoms and the detection rates of infections vary by age (Gornyk et al., 2021). According to that hypothesis, $\hat{n}_{i j k}$ are functions of the weekly test numbers of the corresponding age group and week in the same country $t_{i j k}$, say $\hat{n}_{i j k}=f\left(t_{i j k}\right)$. This could be quantified by fitting a generalised linear model. However, since we do not know $t_{i j k}$, but only the overall test numbers $t_{j k}$, we cannot derive age-specific models. To approximate the connection between random testing (irrespective of age) and age-specific case numbers, PCA is used. We perform PCA for each country separately on all square root transformed age-specific case time series $^{2}$ as follows:

$$
P_{z j k}=\sum_{i} \lambda_{z i j} \sqrt{\hat{n}_{i j k}}
$$

2 The root transformation ensures that our model cannot predict negative case numbers, along with a reduction of heteroskedasticity in our data. 
with

- $P_{z j k}: z^{\text {th }}$ PC of country $j$ in week $k$

- $\lambda_{z i j}$ : Loading of transformed weekly new cases in age group $i$ on $z^{\text {th }}$ PC of country $j$.

PCA allows us to cover the common trends in the case numbers across all age groups with a small number of indices that are linear combinations of the original variables.

Figure 2 illustrates the loadings of the first PC for each country. Except in the Netherlands, the loadings have a similar bathtub shape, with smaller loadings, in terms of absolute values, for the children and the elderly age groups and larger loadings for the working-age population. For the Netherlands, we observe a monotonously decreasing trend by age. Large absolute loadings represent a high correlation between the PCs and the corresponding age groups, and vice versa. There is an inverse relationship between the PCs and age-specific case numbers, which is represented by the negative signs of the loadings. Hence, increases in these

\section{Figure 2:}

Loadings of first principal components of square roots of age-specific weekly case numbers by country
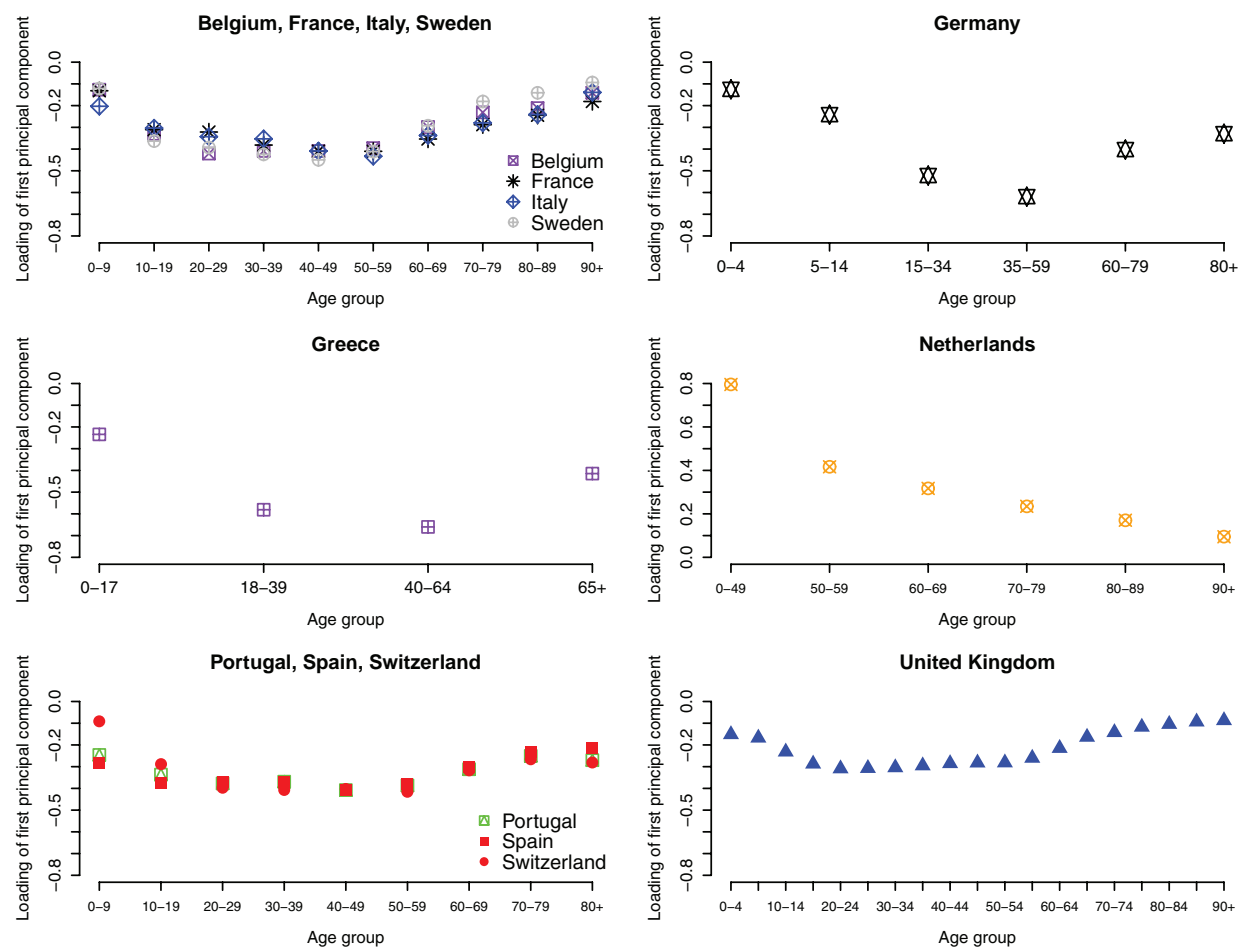

Source: Own computation. 
PCs are associated with decreasing weekly case numbers of the corresponding age groups, and vice versa. ${ }^{3}$ For all countries, the respective first $\mathrm{PCs}^{4}$ explain $93-99 \%$ of the variance in the square roots of age-specific weekly new case numbers over the year 2020, and are therefore sufficient to explain the major age-specific trends in case numbers.

We see that decreases in the $\mathrm{PCs}^{5}$ are associated with increases in case numbers to varying degrees for different age groups. Looking at the example of Greece, we see (absolute) smaller loadings in the 0-17 and 64 and older age groups, and larger loadings for the 18-64 age group. Therefore, a decrease in that PC is associated, ceteris paribus, with more distinct increases in the case numbers among individuals aged 18-64 than among the younger and the elderly populations. As $P_{1 j k}$ is a linear combination of the age-specific case numbers according to (5), we can quantify some connection $P_{1 j k}=g\left(t_{j k}\right)$, which is used to investigate the statistical association of $P_{1 j k}$ to the overall weekly test numbers in country $j$. PCs account for the differences in detection rates indirectly, as we first quantify the test number coefficient in a regression of $P_{1 j k}$ on the tests. After deriving the coefficient of $t_{j k}$ in $P_{1 j k}=g\left(t_{j k}\right)$ by the maximum likelihood, we can then predict the expected value of $P_{1 j k}$ based on a given number of tests. By plugging in the predicted values of all $P_{z j k}$ in (5), while holding all $P_{z j k}$ with $z \neq 1$ fixed, we have a system of linear equations, which, given that we predict all $P_{z j k}$ after test adjustment and know all $\lambda_{z i j}$ from singular value decomposition, we can derive predicted age-specific case numbers $\hat{n}_{i j k}$ from (5) after test adjustment without having access to age-specific test numbers.

The impact of testing on the case numbers and the detection rates of infections is investigated in a causal regression, as described above. However, it is important to separate increases in case numbers due to increases in infection numbers from those caused by more testing, and, hence, higher detection rates. Increases in test rates might be caused by a shift in the political agenda, such as a move to increase the number of random tests in order to detect more asymptomatic infections, or a response to higher numbers of infections that includes more testing of suspected cases (e.g., of individuals who have come into contact with confirmed cases). We investigate this connection through regression analysis as follows: for each country, the first PC is regressed on the first lag of official COVID-19 cases together with the weekly tests:

$$
P_{1 j k}=\alpha_{j}+\beta_{j} \hat{n}_{. j k-1}+\gamma_{j} t_{j k}
$$

with

- $P_{1 j k}$ : value of PC1 for country $j$ in week $k$

\footnotetext{
3 For the Netherlands, increases of PC1 are associated with increases in case numbers because the loadings are positive.

4 The total number of PCs for each country equals the number of age groups; e.g., the number of PCs for Belgium, France, Italy and Sweden is 10.

5 Or increases for the case of the Netherlands.
} 
- $\alpha_{j}, \beta_{j}, \gamma_{j}$ : country-specific parameters estimated via ordinary least squares

- $t_{j k}$ : number of tests conducted in country $j$ during week $k$.

The $k$ th residual from (6) shall be named $\varepsilon_{j k}$.

The model assumes that the observed cases are affected by the number of tests performed in the current week, which is, however, affected by both politically driven decisions and concrete increases in infection activity in the previous week. Therefore, $\hat{n}_{. j k-1}$ serves as a control variable in the analysis that includes increases in both the numbers of infections and the share of positive tests. By using this approach, we mitigate potential bias in our interpretation of the connection between contemporaneous increases in both test and case numbers. After fitting country-specific models following (6), we adjust the observed case numbers for underestimation, and, thus, underdetection, by holding the control variable $\hat{n}_{. j k-1}$ as observed and adjusting the test variable $t_{j k}$ to a specific value. This enables us to predict the number of cases we would, ceteris paribus, have expected to find given a fixed number of random tests each week that are not connected to observed positive cases. That value is in essence arbitrary. However, it appears plausible to set countryspecific constants to account for the population size of each country. According to the ECDC (European Centre for Disease Prevention and Control, 2021b), among the study countries, the maximum outcome of the tests performed was around 5.7\% of the estimated population, found for Portugal in calendar week 47. Therefore, we set our maximum of hypothetical weekly test numbers to $\tilde{t}_{j}=\max \left(t_{P T}\right) \cdot \frac{B_{j}}{B_{P T}}$, with $\max \left(t_{P T}\right)$ being the maximum outcome of the weekly tests performed in Portugal, $B_{P T}$ being the population estimate for Portugal and $B_{j}$ being the population estimate for country $j$. Let us define $\tilde{P}_{1 j k}$ as the hypothetical value we would have observed for $P_{1 j k}$ for a test number fixed at $\tilde{t}_{j}$. The prediction of $\tilde{P}_{1 j k}$ is then:

$$
\mathbb{E}\left[\tilde{P}_{1 j k}\right]:=\mathbb{E}\left[P_{1 j k} \mid t_{j k}=\tilde{t}_{j}\right]=\hat{\alpha}_{j}+\hat{\beta}_{j} \hat{n}_{. j k-1}+\hat{\gamma}_{j} \tilde{t}_{j k},
$$

where $\hat{\alpha}_{j}, \hat{\beta}_{j}$ and $\hat{\gamma}_{j}$ are country-specific parameter estimates derived by OLS regression according to (6). As infection time series are not stationary, but instead move in waves of peaks and troughs, a simple adjustment according to (7) would not include these seasonal patterns in the development of infections. To incorporate this seasonality into our adjustment, we add the residuals extracted from (6), and adjust our prediction from (7) to infection trends above or below expectations caused by the wave-like development of infections. We assume that the observed derivations from the case numbers expected from our model under the observed test and the previous case numbers would carry over, even under a specified number of tests. The adjustment of the PCs is therefore

$$
\tilde{P}_{1 j k}=\hat{\alpha}_{j}+\hat{\beta}_{j} \hat{n}_{. j k-1}+\hat{\gamma}_{j} \tilde{\tau}_{j}+\varepsilon_{j k}
$$

For each country, the remaining PCs are unchanged. Let $\tilde{\boldsymbol{P}}_{j}$ be the matrix of testadjusted PCs for country $j$. We then derive the square roots of the test-adjusted 
weekly case numbers for country $j$ by

$$
\tilde{M}_{i j}=\tilde{\boldsymbol{P}}_{j} \times \Lambda_{j}^{-1},
$$

with

- $\tilde{M}_{i j}$ : the matrix of the square $\operatorname{roots}^{6}$ of the test-adjusted age-specific weekly case numbers of country $j$,

- $\Lambda_{j}^{-1}$ : the inverse of the loadings matrix of country $j$.

Finally, we compute the squares for all elements of (9), which are then test-adjusted case numbers, say $\tilde{n}_{i j k}=\left(m_{i j k}\right)^{2}$, with $m_{i j k}$ being the element in the $i$ th row and the $k$ th column of the matrix $\tilde{\boldsymbol{M}}_{i j}$.

We will then compute the test-adjusted age-specific CFRs by

$$
\widetilde{C F R} i j k=\frac{D_{i j k}}{\tilde{N}_{i j k}}
$$

with $\tilde{N}_{i j k}$ being the sum of the weekly test-adjusted age-specific case numbers up to week $k$ in country $j$. Using this, we derive the age- and test-adjusted CFR estimates over time, similar to (3):

$$
C F R_{j k}^{a g e, t e s t}=\sum_{i} w_{i} \times \widetilde{C F R_{i j k}}
$$

\subsection{Step III: Investigate bias in CFRs due to delays between the reporting of cases and deaths}

In the third step, we investigate the effects of different lags between case reports and deaths on the CFR estimates. The unknown distribution of the time lag of $\Delta$ weeks between the reporting of a case and death is considered. Verity et al. (2020) estimated the average time from infection to death to be about 14 days. For instance, the age-specific and lag-adjusted CFR of age group $i$, in country $j$, in week $k$, based on a lag of the cases of $\Delta$ weeks is

$$
\breve{C F R}_{i j k-\Delta}=\frac{D_{i j k}}{\hat{N}_{i j k-\Delta}} .
$$

The age- and lag-adjusted $\mathrm{CFR}^{7}$ is then similar to (4):

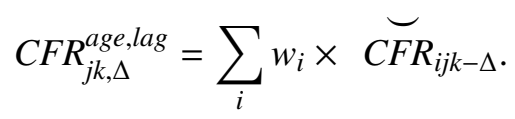

\footnotetext{
6 The initial use of square roots ensures the non-negativity of the predicted case numbers, since we eventually take the squares of the square roots of the cases we predict from PCA.

7 In the next section, we will explain why we do not include testing here.
} 
We compare this measure for the pandemic over the study period and for all countries with $\Delta=0,1,2,3$; with $\Delta=0$ being the case of the age-adjusted CFR, as in (4). We will provide the results in Section 3.3.

\subsection{Step IV: Investigation of the effects of healthcare system capacity and occupancy on CFRs}

For our investigation of the impact of healthcare system capacity on CFRs, we use estimates of the available intensive care unit (ICU) beds per 1,000 inhabitants provided by the OECD (2021a), and the weekly means of daily ICU bed occupancies $I_{. j k}$ provided by the ECDC (European Centre for Disease Prevention and Control, 2021a) for seven of our study countries. For the countries for which these data are not available, we instead use hospital beds per 1,000 inhabitants together with weekly counts of new cases. Hospital admissions due to COVID-19 for the previous $\gamma$ weeks are addressed as $h_{. j k, \gamma}$. First, we give a qualitative assessment using graphical analysis of the connection between CFRs and healthcare capacity and occupancy. To compare the hospital bed capacities in the study countries, we adjust the weekly numbers of new hospitalisations, as provided by the ECDC (European Centre for Disease Prevention and Control, 2021a), by the bed capacities per 1,000 inhabitants. These figures are provided as static estimates by the OECD (2021b). As both variables are measured relative to each country's population, dividing them leads to an admission-per-hospital bed measure in percent, defined as

$$
h_{. j k, \gamma}^{a d j}=\frac{h_{. j k, \gamma}}{\bar{b}_{j}},
$$

with $\bar{b}_{j}$ denoting the per 100,000 inhabitant number of available hospital beds in country $j$. While this measure has its merits, as it is static and thus does not change over time, it should be seen as a rough adjustment parameter that accounts for the differences between national healthcare system capacities. Similarly, the connection between age-adjusted CFRs and ICU occupancies is investigated as

$$
\mathcal{I}_{. j k}^{a d j}=\frac{I_{. j k}}{\bar{c}_{j}},
$$

with $\bar{c}_{j}$ being the estimates of the national ICU beds available. As the latter estimates are not available from the OECD, we use the latest available estimates provided by Our World in Data (2021).

\section{Results}

We will now present the results from our adjustments of the crude CFR for each step described in Section 2, and provide a measure that is most appropriate for 
quantifying case fatality risks for the study countries given the available data. Specifically, we will compare the crude CFR without any adjustment (addressed by M1) with the age-standardised CFR, as derived following the approach described in Section 2.1 (M2); the adjusted CFR after age standardisation and test adjustment (M3); and the adjusted CFR after age standardisation and lag adjustment (M4). Finally, we will investigate the impact of hospitalisations on the CFR.

\subsection{Impact of age standardisation on CFR estimates}

Age-standardised CFRs for the study countries are illustrated in Figure 3, with Figure 3(a) again displaying estimates for the study countries in central and northern Europe, and Figure 3(b) providing estimates for the study countries in the Mediterranean region.

The courses of the age-standardised curves are more stable than those of the crude CFR curves. A large share of the decreases in the crude CFRs observed since spring 2020 vanishes when accounting for the age structure of the cases. In general, the weekly investigation smooths out some of the variations that appear in daily monitoring. In particular, some of the peaks shown in Figure 1 are smoothed out to a large extent. While international differences are still observable, the curves converge to a greater degree than is the case for the crude CFRs. The strong peak for France is a statistical artifact caused by the change in the input data in calendar week 33. The horizontal line again represents the mean of all observations of the CFR with an age structure according to the European Standard Population. The variance between this line and the age-standardised CFR curves has, compared to that of the crude CFR, decreased substantially. We understand that the crude CFR curves between countries are skewed due to the age structure of the cases, especially in the early stages of the pandemic. While $c v(M 1)^{8}$ of the initial crude CFRs is around $72 \%$, the age standardisation decreases this value to $c v(M 2)^{9} \approx 51 \%$. Hence, a large share of the international and intertemporal variance in the CFR is explained by the demographics of the cases.

\subsection{Impact of test adjustment on CFR estimates}

Regarding test adjustment, our regression models estimated following (6) for all countries shows a highly statistically significant effect of testing on the PCs, and thus on the weekly numbers of new cases, even when controlling for the first lag of

8 Crude CFR without any adjustment.

9 Age-standardised CFR as derived following the approach described in Section 2.1. 
Figure 3:

Age-standardised CFR estimates (the horizontal line represents the mean of the daily age-standardised CFR estimates over all dates and countries)

a) Central and Northern Europe

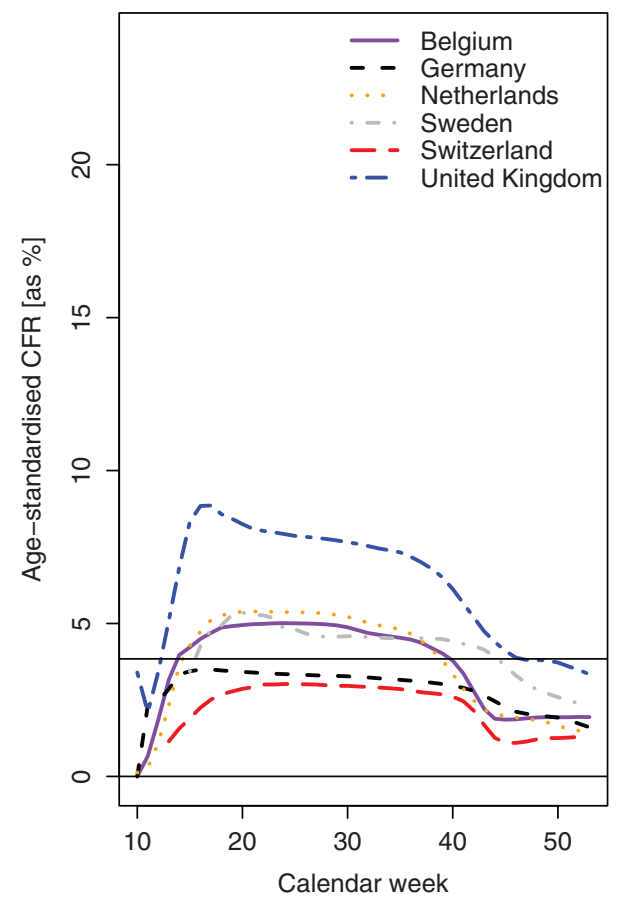

b) Mediterranean

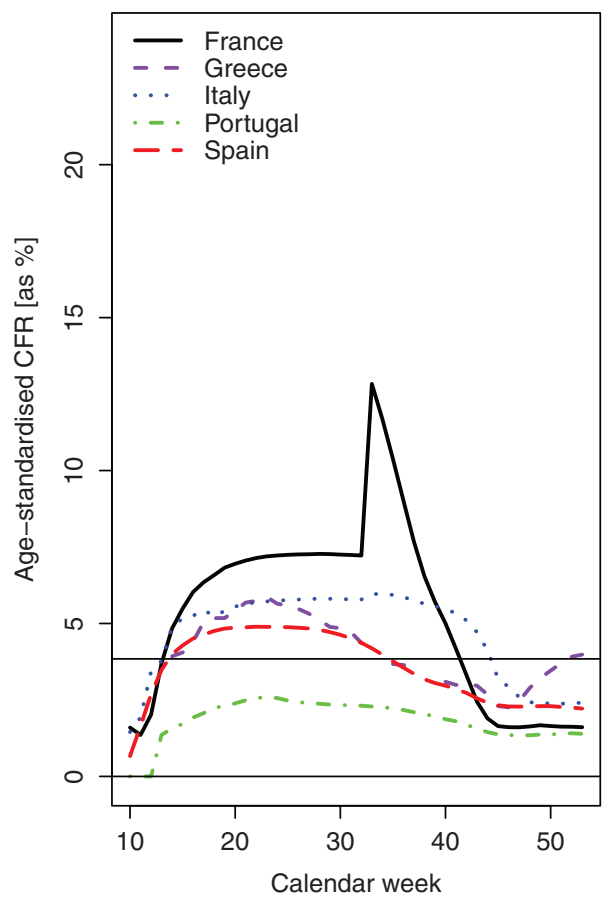

Source: European Union (2013); Instituto de Salud Carlos III (2020a, 2020b); Istituto Superiore di Sanità (2020a, 2020b, 2020c, 2020d); Johns Hopkins University (2021); Robert Koch Institut (2021); Santé publique France (2020a, 2020b); own computation.

the new case numbers. Figure 4 illustrates this finding via quantile-quantile plots of the model fits for each country. ${ }^{10}$

However, the adjustment of cases to testing leads to a considerable worsening of the CFR model, with $c v(M 3)^{11} \approx 124 \%$. We conclude that the testing strategy has an effect on the case numbers. However, our approach of including this finding in CFR estimation does not lead to improvements. Therefore, in our further analysis, we proceed without a test adjustment. However, our results imply that the

10 We checked lin-log models as well. For simplicity, we show here the plots of the lin-lin models only.

11 Adjusted CFR after age standardisation and test adjustment. 
Figure 4:

Quantile-quantile plots of testing model fits for first PCs of age-specific case numbers
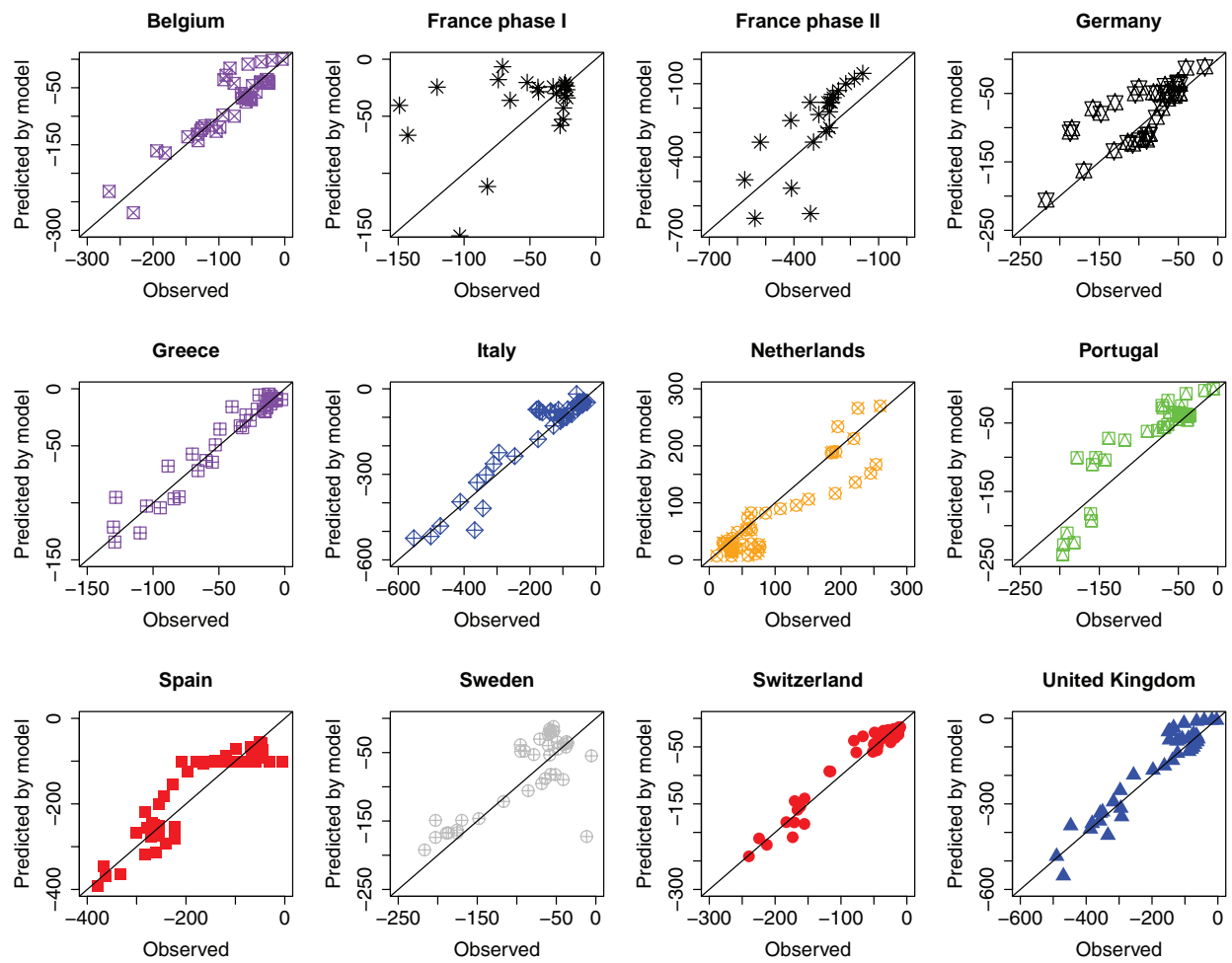

Source: Own computation.

differences found in case fatality estimates stem at least in part from differences between countries in levels of underdetection.

\subsection{Impact of lag adjustment on CFR estimates}

The lag adjustments according to (12) and (13) do not provide improvements in the CFR estimates, but instead worsen them, with, e.g., a $c v(M 4)^{12} \approx 107 \%$ employing the first weekly lag of cases. This pattern is especially apparent for the early stages of the pandemic, for which the CFRs are highly overestimated. Therefore, pure age standardisation, as done in M2, gives the most stable CFR estimates.

12 Adjusted CFR after age standardisation and lag adjustment. 
Figure 5:

Connection between age-standardised CFRs and ICU bed occupancy

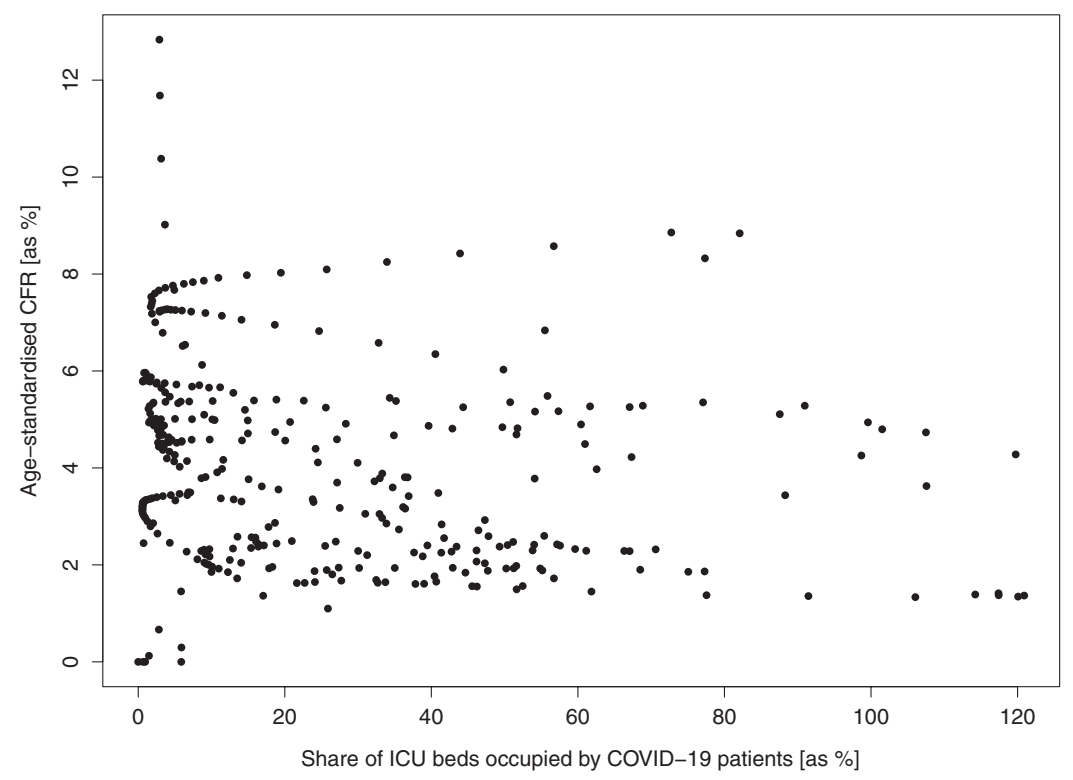

Source: European Centre for Disease Prevention and Control (2021a); Human Mortality Database (2021); Our World in Data (2021); Own computation.

\subsection{Impact of hospitalisations on CFR estimates}

Figures 5 and 6 display scatterplots of the age-standardised CFRs, regardless of the country ${ }^{13}$ against $\mathcal{I}_{. j k}^{a d j}$ and $h_{. j k, \gamma}^{a d j}$, respectively, over the study period without any lags, with lags of no and one week, with lags of the previous two weeks and with lags of the previous three weeks, respectively. Regardless of which lags are chosen for the COVID-19-related hospitalisations, or of whether we use the daily ICU occupancy, the age-standardised CFRs do not show any statistical correlation between the chosen healthcare hospital burden variable and the age-adjusted COVID-19-specific fatality rates.

\footnotetext{
13 We checked this by country as well, but the outcome did not change significantly when individual countries were examined.
} 
Figure 6:

Connection between age-standardised CFRs and new hospitalisations
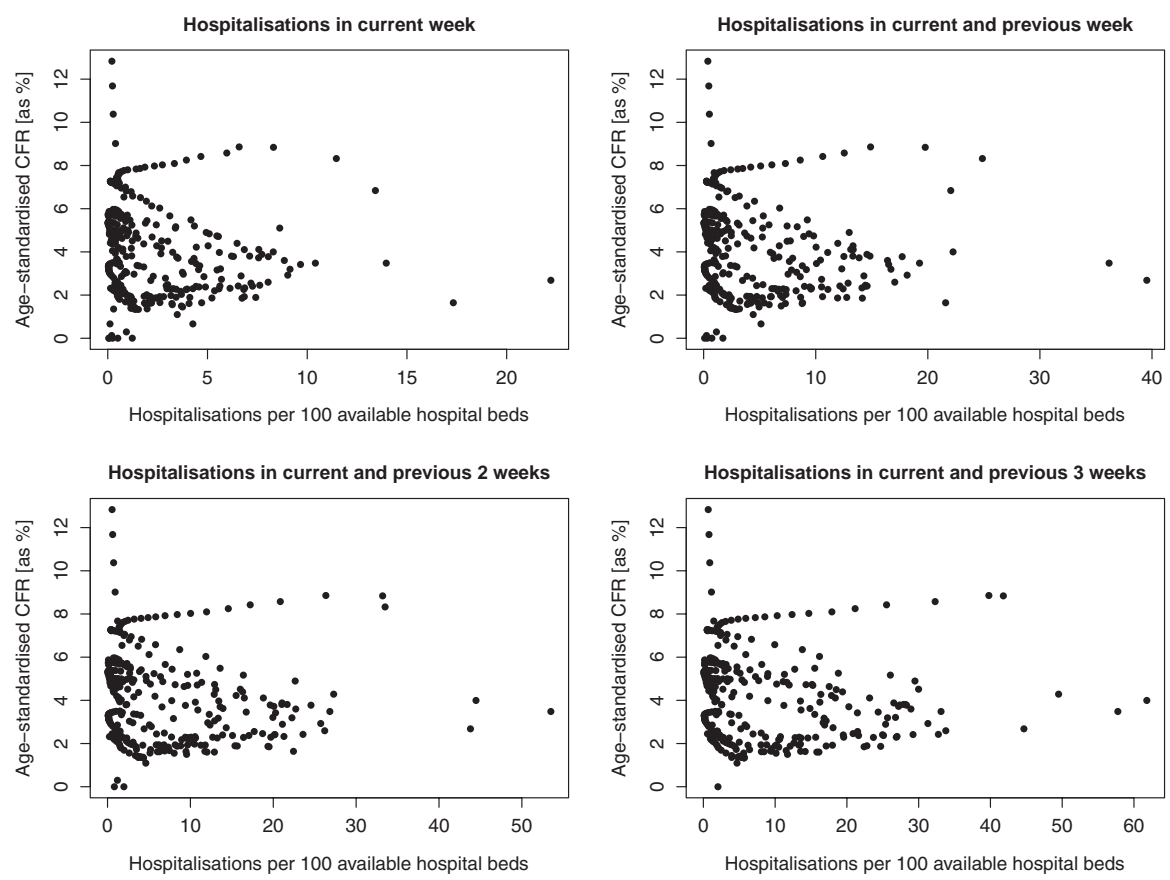

Source: European Centre for Disease Prevention and Control (2021a); OECD (2021b); Human Mortality Database (2021); Own computation.

\section{Discussion and conclusion}

The results of our analysis indicate that there are large differences in the reported CFRs of different countries. We discussed factors derived from the literature that may help to explain these differences. We presented evidence that a large proportion of the differences in CFRs between the 11 countries investigated here can be attributed to differences in the countries' age distributions of cases and testing policies. Our analysis also showed, however, that given the available data, employing age-standardised CFRs provides the most stable intertemporal and international CFR estimates for the first year of the pandemic. Although we found that testing had a clear impact on the case numbers, and, in turn, on the CFR estimates, which affected different age groups very differently, with the level of underestimation of infections being especially high in the working-age group, we lacked sufficient information on detection rates to derive better CFR estimates by employing our test adjustment. Future studies may use detection rates derived 
from population-based studies of infection frequency (either seroprevalence or longitudinal PCR-based surveys) to adjust for the underdetection of infections.

We did not find that a lag adjustment of the case numbers for the computation of CFRs led to improvements in the estimates. Moreover, we did not find a statistical connection between healthcare system capacity and CFRs, which we checked using ICU occupancy as well as hospitalisations. Neither of these approaches identified any connection between the national healthcare systems and the CFR estimates.

However, there were still differences in CFRs between the countries and over the year that could not be explained by the factors investigated here. Future research could address those differences in more detail. We should keep in mind, however, that there are general differences in age-specific mortality rates between the countries investigated here (Vanella, 2017). A more thorough comparative international analysis might take these differences in general mortality into account as well. Certainly, there are other factors that also play into country-specific differences, including environmental factors, such as air pollution or climate conditions (Contini and Costabile, 2020). A limitation of our contribution is related to the latency of infections. We do not know the real number of infections in the population. To account for this gap in our knowledge, we included the weekly test rates in a PC approach, along with age-specific sensitivities to testing. More information on detection rates would improve our test adjustment of cases, and could shed more light on the remaining variation observed here. Regarding the age-standardised CFR, it is important to note that this indicator is not a real CFR, but is, rather, a hypothetical CFR we would expect to observe for the population under a hypothetical age structure.

Another important limitation of our work is that public data on the age structure of infected and deceased individuals were found to be missing in public reports on COVID-19 in many European countries. Even for the included countries, these data are only partly available; e.g., they are available only for specific time points, for roughly aggregated age groups or for a selection of all reported cases or deaths. For other countries, age-specific data are not publicly available at all. Moreover, many countries do not even provide data stratified by sex. This lack of appropriate data biases our understanding of the severity of the disease, as there are significant gender differences in susceptibility to severe disease and general mortality (Fernández Villalobos et al., 2021; Luy and Di Giulio, 2006; Spagnolo et al., 2020; Vanella, 2017; Vanella et al., 2020, 2021). As the age groups in the reported data differ across countries as well, there appears to be a bias in international age standardisation that should be taken into account when considering our results. For the analysis of the association between fatalities and the healthcare load as measured by hospitalisations and individuals in intensive care due to COVID-19, we could not incorporate the age structure or the severity of hospitalised cases into our computations because these data are not available.

Thus, our results suggest that to allow for a more sophisticated statistical analysis, further improvements in age-specific data on cases, deaths and test rates are needed. In particular, more and better data on the connection between infection 
detection rates and testing rates are required, and could significantly improve our understanding of the underestimation of infections in our case data. This could, in turn, lead to more accurate CFR estimates. For analyses of publicly available data to have an impact on public health, better reporting of data on healthcare capacities on a daily or at least a weekly basis is needed. More detailed data on the demographics of cases and deaths, and age-specific test data with infection numbers derived by population-based sentinels, would improve our understanding of the impact of demographic factors on the CFRs, as these data would allow us to include agespecific detection ratios in our investigations. Even health authorities that provide data on the age structure of cases and deaths do not separate the age groups in the same manner. The most important databases give only the crude case and death numbers, without further disaggregation, which might lead to a misinterpretation of the true mortality differences between countries. Moreover, these data would ideally be merged with comorbidity-specific information.

Our study has shown that further progress towards establishing a better coordinated and more unified public health data reporting system in Europe and worldwide is needed to fight the COVID-19 pandemic, and any other pandemic that may emerge in the future.

\section{List of abbreviations}

$\bar{b}_{j} \quad$ Overall available hospital beds per 1,000 inhabitants in country $j$

CFR Case fatality risk

$C F R_{j k}^{a g e}$ Age-standardised case fatality risk for country $j$, in week $k$

$C F R_{j w, \Delta}^{a g e, l a g}$

Age- and lag-adjusted case fatality risk for country $j$, in week $w$, with $\Delta$ weekly lags

$C F R_{i j w}^{a g e, t e s t}$ Age- and test-adjusted case fatality risk for age group $i$, in country $j$, up to week $w$

$d_{i j k} \quad$ Number of deaths in age group $i$, in country $j$, in week $k$

$d_{j k} \quad$ Number of deaths over all age groups, in country $j$, in week $k$

$D_{i j w} \quad$ Cumulative number of deaths for age group $i$, in country $j$, up to week $w$

$D_{. j w}$ Cumulative number of deaths over all age groups, in country $j$, up to week $w$

$\Delta \quad$ Lag length

$h_{j k, \gamma} \quad$ number of hospitalisations per 100,000 inhabitants in country $j$, from weeks $k-\gamma$ to $k$

$\max \{t\} \quad$ Global maximum of weekly tests per 100,000 inhabitants

$n_{i j k} \quad$ Number of infections in age group $i$, in country $j$, in week $k$

$N_{i j k} \quad$ Cumulative number of infections in age group $i$, in country $j$, up to week $w$

$\hat{N}_{i j w}$ Cumulative number of observed cases for age group $i$, country $j$, up to week $w$ 
$\hat{N}_{. j w}$ Cumulative number of observed cases for over all age groups, country $j$, up to week $w$

$\hat{n}_{i j k} \quad$ Number of observed cases in age group $i$, in country $j$, in week $k$

$\hat{n}_{. j k} \quad$ Number of observed cases over all age groups, in country $j$, in week $k$

$\tilde{N}_{i j w} \quad$ Cumulative test-adjusted number of cases in age group $i$, in country $j$, up to week $w$

$\tilde{n}_{i j k}$ Test-adjusted number of cases in age group $i$, in country $j$, in week $k$

$\tilde{n}_{i j k}^{*} \quad$ Lag-weighted and test-adjusted number of cases in age group $i$, in country $j$, in week $k$

$t_{j k} \quad$ Rate of tests per 100,000 inhabitants in country $j$, in week $k$

$w_{i} \quad$ Weight of age group $i$

\section{Funding}

PV, BL and GK received funding from the European Union's Horizon 2020 research and innovation program under grant agreement No 101003480 (project CORESMA) and from the Initiative and Networking Fund of the Helmholtz Association.

\section{Authors' contributions}

PV, HB, CW and BL developed the methods used in this study. PV, HB and CW researched, organised and structured the data, and conducted the computations. BL, $\mathrm{AM}, \mathrm{AH}, \mathrm{SW}, \mathrm{HB}$ and PV did the literature research. PV built the illustrations for the manuscript. All authors wrote the original version of the text. PV revised the manuscript.

\section{Acknowledgments}

We appreciate the knowledgeable and timely remarks by the anonymous reviewers. Moreover, we thank Gabriele Doblhammer, Carlo-Giovanni "Giancarlo" Camarda and Yohann "Jon" Anson for their helpful comments on an earlier version of the paper, which helped us make significant improvements. We are also grateful to Fabian Flaßkamp, who strongly supported the revision of the paper by providing additional country-specific case and death data.

\section{ORCID}

Patrizio Vanella (1) https://orcid.org/0000-0002-6736-6774

Christian Wiessner ${ }^{10}$ https://orcid.org/0000-0001-7943-9881 
Anja Holz ${ }^{(1)}$ https://orcid.org/0000-0002-1688-1805

Gérard Krause https://orcid.org/0000-0003-3328-8808

Annika Möhl (1D https://orcid.org/0000-0003-3274-7216

Berit Lange (iD) https://orcid.org/0000-0002-9325-9307

Heiko Becher ${ }^{(D)}$ https://orcid.org/0000-0002-8808-6667

\section{References}

Brown, C. E. (1998). Applied multivariate statistics in geohydrology and related sciences. Heidelberg: Springer. https://doi.org/10.1007/978-3-642-80328-4

Cai, H. (2020). Sex difference and smoking predisposition in patients with COVID-19. The Lancet Respiratory Medicine, 8(4), E20. https://doi.org/10.1016/S2213-2600(20)30117-X

Contini, D., and Costabile, F. (2020). Does air pollution influence COVID-19 outbreaks? Atmosphere, 11(4), 377. https://doi.org/10.3390/atmos11040377

Davies, N. G., Klepac, P., Liu, Y., Prem, K., Jit, M., Pearson, C. A. B., .. Eggo, R. M. (2020). Age-dependent effects in the transmission and control of COVID-19 epidemics. Nature Medicine, 26(8), 1205-1211. https://doi.org/10.1038/s41591-020-0962-9

Dong, E., Du, H., and Gardner, L. (2020). An interactive web-based dashboard to track COVID-19 in real time. The Lancet Infectious Diseases, 20(5), 533-534. https://doi.org/ 10.1016/S1473-3099(20)30120-1

Dudel, C., Riffe, T., Acosta, E., van Raalte, A., Strozza, C., and Myrskylä, M. (2020). Monitoring trends and differences in COVID-19 case-fatality rates using decomposition methods: Contributions of age structure and age-specific fatality. PLoS ONE, 15(9), e0238904. https://doi.org/10.1371/journal.pone.0238904

Eriksson, C. O., Stoner, R. C., Eden, K. B., Newgard, C. D., and Guise, J. M. (2017). The association between hospital capacity strain and inpatient outcomes in highly developed countries: A systematic review. Journal of General Internal Medicine, 32(6), 686-696. https://doi.org/10.1007/s11606-016-3936-3

European Centre for Disease Prevention and Control. (2020a). Novel coronavirus disease 2019 (COVID-19) pandemic: Increased transmission in the EU/EEA and the UK - sixth update. Retrieved from https://www.ecdc.europa.eu/sites/default/files/documents/RRAsixth-update-Outbreak-of-novel-coronavirus-disease-2019-COVID-19.pdf

European Centre for Disease Prevention and Control. (2020b). Sentinel surveillance. Retrieved from https://www.ecdc.europa.eu/en/seasonal-influenza/surveillanceand-disease-data/facts-sentinel-surveillance

European Centre for Disease Prevention and Control. (2021a). Data on hospital and ICU admission rates and current occupancy for COVID-19. Retrieved 08 January 2021, from https://www.ecdc.europa.eu/en/publications-data/download-data-hospital-and-icuadmission-rates-and-current-occupancy-covid-19

European Centre for Disease Prevention and Control. (2021b). Data on testing for COVID-19 by week and country. Retrieved 08 January 2021, from https://www.ecdc.europa.eu/en/ publications-data/covid-19-testing 
European Union. (2013). Revision of the European standard population: Report of Eurostat's task force. Luxembourg: European Union.

Eurostat. (2019). Eurostat Statistics Explained: Healthcare resources statistics - beds. Retrieved from https://ec.europa.eu/eurostat/statistics-explained/index.php/Healthcare_ resource_statistics_-_beds

Fang, Y., Zhang, H., Xie, J., Lin, M., Ying, L., Pang, P., and Ji, W. (2020). Sensitivity of chest CT for COVID-19: Comparison to RT-PCR. Radiology, 296(2), E115-E117. https://doi.org/10.1148/radiol.2020200432

Federal Office of Public Health. (2021). Coronavirus: Situation in Switzerland. Retrieved 19 July 2021, from https://www.bag.admin.ch/bag/en/home/krankheiten/ausbruecheepidemien-pandemien/aktuelle-ausbrueche-epidemien/novel-cov/situation-schweizund-international.html

Fernández Villalobos, N. V., Ott, J. J., Klett-Tammen, C. J., Bockey, A., Vanella, P., Krause, G., and Lange, B. (2021). Effect modification of the association between comorbidities and severe course of COVID-19 disease by age of study participants: a systematic review and meta-analysis. Systematic Reviews, 10(1), 194. https://doi.org/10.1186/s13643-02101732-3

Gianicolo, E., Riccetti, N., Blettner, M., and Karch, A. (2020). Epidemiological measures in the context of the COVID-19 Pandemic. Deutsches Ärzteblatt International, 117, 336-342. https://doi.org/10.3238/arztebl.2020.0336

Gordis, L. (2014). Epidemiology (5th ed.). Philadelphia: Elsevier Saunders.

Gornyk, D., Harries, M., Glöckner, S., Strengert, M., Kerrinnes, T., Heise, J.-K., . . MuSPAD Team. (2021). SARS-CoV-2 seroprevalence in Germany: A population-based sequential study in seven regions. Deutsches Ärzteblatt International, 118. https://doi.org/10.3238/ arztebl.m2021.0364

Human Mortality Database. (2021). University of California, Berkeley (USA), and Max Planck Institute for Demographic Research (Germany). Human Mortality Database. Retrieved 19 July 2021, from www.mortality.org

Instituto de Salud Carlos III. (2020a). Informe sobre la situación de COVID-19 en España. Informe COVID-19 $n^{\circ}$ 6-32. 05 de marzo - 21 de mayo de 2020. Retrieved between 23 March 2020 and 05 January 2021, from https://www.isciii.es/QueHacemos/Servicios/ VigilanciaSaludPublicaRENAVE/EnfermedadesTransmisibles/Paginas/InformesCOVID19.aspx

Instituto de Salud Carlos III. (2020b). Informes $n^{\circ}$ 34-59. Situación de COVID-19 en España. Casos diagnosticados a partir 10 de mayo. Informe COVID-19. 15 de julio - 29 de diciembre de 2020. Retrieved between 23 March 2020 and 05 January 2021, from https://www.isciii.es/QueHacemos/Servicios/VigilanciaSaludPublicaRENAVE/ EnfermedadesTransmisibles/Paginas/InformesCOVID-19.aspx

Istituto Superiore di Sanità. (2020a). Epidemia COVID-19. Aggiornamenti nazionali. 19 marzo - 29 dicembre 2020. Retrieved between 10 March 2020 and 04 January 2021, from https://www.epicentro.iss.it/coronavirus/sars-cov-2-sorveglianza-dati

Istituto Superiore di Sanità. (2020b). Letalità in Italia minore di quella della Cina per tutte le fasce di età. Comunicati stampa 16/2020. Retrieved from https://www.iss.it/comunicatistampa/-/asset_publisher/fjTKmjJgSgdK/content/id/5288119 
Istituto Superiore di Sanità. (2020c). Sorveglianza Integrata COVID-19 in Italia. AGGIORNAMENTO 11 marzo 2020. Retrieved 11 March 2020, from https://www.epicentro.iss.it/ coronavirus/sars-cov-2-sorveglianza-dati

Istituto Superiore di Sanità. (2020d). Studio ISS Su 105 deceduti con Covid-2019, età media 81 anni e patologie preesistenti in due terzi dei casi. Comunicati stampa 15/2020. Retrieved from https://www.iss.it/comunicati-stampa/-/asset_publisher/fjTKmjJgSgdK/ content/studio-iss-su-105-deceduti-con-covid-2019-et\%25C3\%25A0-media-81-anni-epatologie-preesistenti-in-due-terzi-dei-casi

Ji, Y., Ma, Z., Peppelenbosch, M. P., and Pan, Q. (2020). Potential association between COVID-19 mortality and health-care resource availability. The Lancet Global Health, 8(4), e480. https://doi.org/10.1016/S2214-109X(20)30068-1

Johns Hopkins University. (2021). COVID-19 Dashboard by the Center for Systems Science and Engineering (CSSE) at Johns Hopkins University (JHU). Retrieved 15 January 2021, from https://gisanddata.maps.arcgis.com/apps/opsdashboard/index.html\# /bda7594740fd40299423467b48e9ecf6

Jordan, R. E., Adab, P., and Cheng, K. K. (2020). COVID-19: risk factors for severe disease and death - A long list is emerging from largely unadjusted analyses, with age near the top. BMJ, 368, m1198. https://doi.org/10.1136/bmj.m1198

Lau, H., Khosrawipour, V., Kocbach, P., Mikolajczyk, A., Ichii, H., Schubert, J., ... Khosrawipour, T. (2020). Internationally lost COVID-19 cases. Journal of Microbiology, Immunology and Infection, 53(3), 454-458. https://doi.org/10.1016/j.jmii.2020.03.013

Legido-Quigley, H., Asgari, N., Teo, Y. Y., Leung, G. M., Oshitani, H., Fukuda, K., ... Heymann, D. (2020). Are high-performing health systems resilient against the COVID-19 epidemic? Lancet, 395(10227), 848-850. https://doi.org/10.1016/S0140-6736 (20)30551-1

Li, R., Pei, S., Chen, B., Song, Y., Zhang, T., Yang, W., and Shaman, J. (2020). Substantial undocumented infection facilitates the rapid dissemination of novel coronavirus (COVID19). Science, 368(6490), 489-493. https://doi.org/10.1126/science.abb3221

Lipsitch, M. (2020). Correspondence to: Estimating case fatality rates of COVID-19. Lancet Infectious Diseases, 20(7), 775. https://doi.org/10.1016/S1473-3099(20)30245-0

Lipsitch, M., Donnelly, C. A., Fraser, C., Blake, I. M., Cori, A., Dorigatti, I., .. . Hernan, M. A. (2015). Potential biases in estimating absolute and relative case-fatality risks during outbreaks. PLoS Neglected Tropical Diseases, 9(7), e0003846. https://doi.org/10.1371/ journal.pntd.0003846

Luy, M., and Di Giulio, P. (2006). The impact of health behaviors and life quality on gender differences in mortality. In J. K. Geppert, J. (Ed.), Gender und Lebenserwartung, Gender kompetent - Beiträge aus dem GenderKompetenzZentrum (Vol. 2, pp. 113-147). Bielefeld: Kleine.

Ministère des Solidarités et de la Santé. (2021). Données relatives à l'épidémie de COVID-19 en France: vиe d'ensemble. Retrieved from https://www.data.gouv.fr/en/datasets/donneesrelatives-a-lepidemie-de-covid-19-en-france-vue-densemble/\#_

OECD. (2021a). Beyond Containment: Health systems responses to COVID-19 in the OECD. OECD policy responses to Coronavirus (COVID-19), OECD Publishing, Paris, https://doi.org/10.1787/6ab740c0-en 
OECD. (2021b). Hospital beds (indicator). Retrieved 01 March 2021, from https://data.oecd. org/healtheqt/hospital-beds.htm

Onder, G., Rezza, G., and Brusaferro, S. (2020). Case-fatality rate and characteristics of patients dying in relation to COVID-19 in Italy. JAMA, 323(18), 1775-1776. https://doi. org/10.1001/jama.2020.4683

Our World in Data. (2021). Intensive care beds per 100,000 people, 2020. Retrieved 25 August 2021, from https://ourworldindata.org/grapher/intensive-care-beds-per-100000

Pan, Y., Zhang, D., Yang, P., Poon, L. L. M., and Wang, Q. (2020). Viral load of SARS-CoV-2 in clinical samples. Lancet Infectious Diseases, 20(4), 411-412. https://doi.org/10.1016/ s1473-3099(20)30113-4

Public Health England. (2021a). Coronavirus (COVID-19) in the UK. Retrieved 12 July 2021, from https://coronavirus.data.gov.uk/details/download

Public Health England. (2021b). Testing in United Kingdom. Retrieved 19 July 2021, from https://coronavirus.data.gov.uk/details/testing

Rajgor, D. D., Lee, M. H., Archuleta, S., Bagdasarian, N., and Quek, S. C. (2020). The many estimates of the COVID-19 case fatality rate. Lancet Infectious Diseases, 20(7). https://doi.org/10.1016/S1473-3099(20)30244-9

Reich, N. G., Lessler, J., Cummings, D. A. T., and Brookmeyer, R. (2012). Estimating absolute and relative case fatality ratios from infectious disease surveillance data. Biometrics, 68(2), 598-606. https://doi.org/10.1111/j.1541-0420.2011.01709.x

Rhodes, A., Ferdinande, P., Flaatten, H., Guidet, B., Metnitz, P. G., and Moreno, R. P. (2012). The variability of critical care bed numbers in Europe. Intensive Care Medicine, 38(10), 1647-1653. https://doi.org/10.1007/s00134-012-2627-8

Riffe, T., Acosta, E., Aburto, J. M., Alburez-Gutierrez, D., Altová, A., Alustiza, A., ... Zarulli, V. (2021a). COVerAGE-DB: a global demographic database of COVID-19 cases and deaths. Retrieved 14 July 2021, from https://github.com/timriffe/covid_age

Riffe, T., Acosta, E., Aburto, J. M., Alburez-Gutierrez, D., Altová, A., Alustiza, A., ... Zarulli, V. (2021b). Data resource profile: COVerAGE-DB: A global demographic database of COVID-19 cases and deaths. International Journal of Epidemiology, 50(2), 390-390f. https://doi.org/10.1093/ije/dyab027

Robert Koch Institut. (2020a). SARS-CoV-2-Testkriterien für Schulen während der COVID-19-Pandemie. Empfehlungen des Robert Koch-Instituts für Schulen. Retrieved from https://www.rki.de/DE/Content/InfAZ/N/Neuartiges_Coronavirus/Teststrategie/NatTeststrat.html

Robert Koch Institut. (2020b). Syphilis in Deutschland 2019 - Neuer Höchststand von Infektionen; SARS-CoV-2-Testzahlen in Deutschland. Epidemiologisches Bulletin, 2020(49). Retrieved from https://www.rki.de/DE/Content/Infekt/EpidBull/Archiv/2020/ Ausgaben/49_20.pdf?_blob=publicationFile

Robert Koch Institut. (2021). RKI COVID19. Retrieved 04 January 2021, from https://www. arcgis.com/home/item.html?id=f10774f1c63e40168479a1feb6c7ca74

Santé publique France. (2020a). COVID-19: Point épidémiologique - Situation au 4-15 mars 2020 à minuit. Retrieved 15 March 2020, from https://www.santepubliquefrance.fr/ recherche/\#search=COVID-19\%20:\%20point\%20\%C3\%A9pid\%C3\%A9miologique 
Santé publique France. (2020b). COVID-19: Point épidémiologique hebdomaire du 24 mars - 31 décembre 2020. Retrieved from 27 March 2020 to 04 January 2021, from https://www.santepubliquefrance.fr/

Shim, E., Tariq, A., Choi, W., Lee, Y., and Chowell, G. (2020). Transmission potential and severity of COVID-19 in South Korea. International Journal of Infectious Diseases, 93, 339-344. https://doi.org/10.1016/j.ijid.2020.03.031

Spagnolo, P. A., Manson, J. E., and Joffe, H. (2020). Sex and gender differences in health: What the COVID-19 Pandemic can teach us. Annals of Internal Medicine, 173(5), 385386. https://doi.org/10.7326/M20-1941

Spychalski, P., Blazynska-Spychalska, A., and Kobiela, J. (2020). Correspondence to: Estimating case fatality rates of COVID-19. Lancet Infectious Diseases, 20(7), 774-775. https://doi.org/10.1016/S1473-3099(20)30246-2

Vanella, P. (2017). A principal component model for forecasting age- and sex-specific survival probabilities in Western Europe. Zeitschrift für die gesamte Versicherungswissenschaft (German Journal of Risk and Insurance), 106(5), 539-554. https://doi.org/10.1007/ s12297-017-0393-y

Vanella, P. (2018). Stochastic forecasting of demographic components based on principal component analyses. Athens Journal of Sciences, 5(3), 223-245. https://doi.org/10.30958/ ajs.5-3-2

Vanella, P., Basellini, U., and Lange, B. (2021). Assessing excess mortality in times of pandemics based on principal component analysis of weekly mortality data-the case of COVID-19. Genus: Journal of Population Sciences, 77(16). https://doi.org/10.1186/ s41118-021-00123-9

Vanella, P., Heß, M., and Wilke, C. B. (2020). A probabilistic projection of beneficiaries of long-term care insurance in Germany by severity of disability. Quality $\mathcal{G}$ Quantity: International Journal of Methodology, 54(3), 943-974. https://doi.org/10.1007/s11135020-00968-w

Verity, R., Okell, L. C., Dorigatti, I., Winskill, P., Whittaker, C., Imai, N., ... Ferguson, N. M. (2020). Estimates of the severity of coronavirus disease 2019: a model-based analysis. Lancet Infectious Diseases, 20(6), 669-677. https://doi.org/10.1016/S14733099(20)30243-7

Wilson, N., Kvalsvig, A., Barnard, L. T., and Baker, M. G. (2020). Case-fatality risk estimates for COVID-19 calculated by using a lag time for fatality. Emerging Infectious Diseases, 26(6), 1339-1441. https://doi.org/10.3201/eid2606.200320

World Health Organization. (2020a). Laboratory testing for 2019 novel coronavirus (2019-nCoV) in suspected human cases. Interim guidance. Retrieved $10 \mathrm{March}$ 2020, from https://www.who.int/publications-detail/laboratory-testing-for-2019-novelcoronavirus-in-suspected-human-cases-20200117

World Health Organization. (2020b). Assessing National Capacity for the Prevention and Control and Noncommunicable Diseases: Report of the 2019 Global Survey. Geneva: World Health Organization. https://www.who.int/publications/i/item/ncd-ccs-2019

Wu, J. T., Leung, K., Bushman, M., Kishore, N., Niehus, R., de Salazar, P. M., ... Leung, G. M. (2020). Estimating clinical severity of COVID-19 from the transmission dynamics in Wuhan, China. Nature Medicine, 26, 506-510. https://doi.org/10.1038/s41591-020 -0822-7 
Wu, Z., and McGoogan, J. M. (2020). Characteristics of and important lessons from the coronavirus disease 2019 (COVID-19). Summary of a Report of 72314 cases from the chinese center for disease control and prevention. JAMA, 323(13), 1239-1242. https: //doi.org/10.1001/jama.2020.2648

Xie, J., Tong, Z., Guan, X., Du, B., Qiu, H., and Slutsky, A. S. (2020). Critical care crisis and some recommendations during the COVID-19 epidemic in China. Intensive Care Medicine, 46(5), 837-840. https://doi.org/10.1007/s00134-020-05979-7

Yang, J., Zheng, Y., Gou, X., Pu, K., Chen, Z., Guo, Q., ... Zhou, Y. (2020). Prevalence of comorbidities in the novel Wuhan coronavirus (COVID-19) infection: a systematic review and meta-analysis. International Journal of Infectious Diseases, 94, 91-95. https: //doi.org/10.1016/j.ijid.2020.03.017

Zhang, J. J., Dong, X., Cao, Y. Y., Yuan, Y. D., Yang, Y. B., Yan, Y. Q., ... Gao, Y. D. (2020). Clinical characteristics of 140 patients infected with SARS-CoV-2 in Wuhan, China. Allergy, 75(7), 1730-1741. https://doi.org/10.1111/all.14238

Zhou, F., Yu, T., Du, R., Fan, G., Liu, Y., Liu, Z., ... Cao, B. (2020). Clinical course and risk factors for mortality of adult inpatients with COVID-19 in Wuhan, China: a retrospective cohort study. Lancet, 395(10229), 1054-1062. https://doi.org/10.1016/S0140-6736(20) 30566-3

Open Access This article is published under the terms of the Creative Commons Attribution 4.0 International License (https://creativecommons.org/licenses/by/4.0/) that allows the sharing, use and adaptation in any medium, provided that the user gives appropriate credit, provides a link to the license, and indicates if changes were made. 